\title{
Road Traffic Injuries among Women Brought to the Largest Tertiary Hospital in the Philippines
}

\author{
Jinky Leilanie Lu, MOH, $\mathrm{PhD}^{1}$ and Sophia Francesca D. Lu, MOS${ }^{2}$ \\ ${ }^{1}$ National Institutes of Health, University of the Philippines Manila \\ ${ }^{2}$ University of the Philippines School of Labor and Industrial Relations
}

\begin{abstract}
Introduction. Road traffic accidents are a growing public health burden, especially in the low- and middle-income countries (LMICs). With resource scarcity, road traffic injuries may lead to poor quality of life among survivors, or deaths at worst. Victims of crashes involving transportations are gendered; therefore, there may be differences in the trends and characteristics of injuries sustained by men and women related to road crash.
\end{abstract}

Objectives. This study aimed to determine the factors related to severity of road crashes among women road users in the Philippines from 2008 to 2017.

Methods. We conducted a retrospective review of clinical records of women patients involved in road crash at the Trauma Division, Department of Surgery of the Philippine General Hospital (PGH) for the ten-year period, January 1, 2008 to December 31, 2017. Data were extracted from the electronic patient records in Integrated Surgical Information System (ISIS).

Results. From 2008 to 2017, 926 of the road crash victims brought to PGH were women. There was an increasing trend, with the years 2015 to 2017 accounting for half of the total cases (55.62\%). The highest cases of women patient admissions were also recorded during the months of June and July (5.61\%). The CALABARZON region (11.23\%) and National Capital Region (8.21\%) had the highest admissions. The patients were most commonly pedestrians (12.20\%) and involved in collisions (13.50\%) or vehicle involvement (13.17\%). The most common vehicle involved was a motorcycle $(9.72 \%)$ followed by car and vans (1.62\%). Only a small proportion of women patients used helmets (3.33\%) and seatbelts (0.12\%). The median length of hospital stay of women patients was 5 days. The most commonly sustained injuries among patients were multiple (83.65\%), external (43.72\%), extremity (33.15\%), head and neck (23.47\%), and face (21.58\%) injuries. Among these, injuries to the extremity had the highest average length of hospital stay (16.04 \pm 31.28 days) while external and head and neck injuries had the shortest $(10.81 \pm 33.42$ days). Multinomial regression showed that women patients who suffered from head and neck, and abdominal injuries had increased odds of dying by 4.94 times (Cl: 2.158-11.302, $p<0.05)$, and 3.33 times (Cl:1.235-9.02, $p<0.05$ ), respectively, compared to those who did not suffer said injuries.

Conclusion. There is a significant number of women involved in road crashes in the Philippines, and therefore, there is a need for directed policies on female road users as vulnerable road users.

Key Words: accidents, traffic, women, motor vehicles, length of stay, hospitalization, Philippines

\section{INTRODUCTION}

Corresponding author: Jinky Leilanie Lu, $\mathrm{MOH}, \mathrm{PhD}$ National Institutes of Health

University of the Philippines Manila

623 Pedro Gil Street, Ermita, Manila 1000, Philippines

Email: jdlu@up.edu.ph
According to a report by the World Health Organization (WHO), road traffic crashes account for 1.35 million deaths worldwide, of which majority is reported among low- and middle-income countries (LMICs). ${ }^{1}$ Ironically, LMICs account for a lesser proportion of vehicles worldwide but experience more road traffic injuries than higher income countries. Road crash injuries do not only lead to death but also poorer quality of life and increased 
injury-related disability-adjusted life years (DALY) among survivors. Road crash injuries, a preventable occurrence, also increase economic costs shouldered by countries and victims, which range from hospital and rehabilitation costs to loss of productivity. Unfortunately, in LMICs such as the Philippines, this data is hard to capture due to the lack of unified information systems and trauma registries. ${ }^{2}$

The Philippines also lacks studies on road traffic injuries that occur in the country. The few local studies on injury and trauma cases have found that road crashes compose most traumatic injuries in emergency department rooms. ${ }^{3}$ Moreover, as the country continues to urbanize and grow, the number of vehicles has also been increasing. Due to the inexpensive option of motorcycles and tricycles, these vehicles have also been the most common mode of transportation among residents yet, these are the most vulnerable modes of travel. ${ }^{4}$ Unfortunately, despite these findings, the Philippines is unable to strongly enforce existing laws that target risky road safety behaviors such as seatbelt and helmet use, drink-driving, and speeding. ${ }^{1,4}$ In addition to these growing concerns, studies show that transportation is gendered, implying that women and men differ in transportation use and methods. ${ }^{5}$ Therefore, it is likely that women and men will also show different trends and characteristics of road crash injuries. The differences in characteristics not only affect the immediate factors leading and surrounding the occurrence of injury, but also have implications on disability experiences and socio-economic situations.

As road crash injuries are known to lead to significant morbidity post-recovery for all genders, it is important to investigate further and provide a female angle to road crash injuries. People with disabilities struggle with the risk of experiencing discrimination; however, this is further aggravated among women with disabilities. ${ }^{6}$ It is important to provide research on the factors involved with road crash injuries and severity among females, which may add to the evidence on how this may be prevented or mitigated.

\section{MATERIALS AND METHODS}

We conducted a retrospective review of clinical records of women patients admitted due to road crash in the Trauma Division, Department of Surgery of the Philippine General Hospital (PGH) during the ten-year period, January 1, 2007 to December 31, 2017 from the electronic patient records in Integrated Surgical Information System (ISIS).

The PGH is a tertiary state-owned hospital operated by the University of the Philippines Manila (UPM). It is designated as the National University Hospital, and the national government referral hospital. The UPM-PGH serves up to 600,000 patients every year. The Philippine General Hospital's Integrated Surgical Information System (PGH-ISIS) houses clinical abstracts of trauma patients to the $\mathrm{PGH}$, from emergency room to inpatient care.
The researchers requested access to the PGH-ISIS portal after securing an approval from the Department of Health-Single Joint Research Ethics Board (DOH-SJREB) and UP Manila Research Ethics Board (UPM-REB). The researchers followed ethical practices and ensured the confidentiality of patient data. Once the request for access to the portal was approved by PGH-ISIS, research assistants with health training such as nurses were given access to the database and encoded data from the clinical abstracts to a predesigned template in Microsoft Excel.

The PGH-ISIS is a system to digitally store clinical abstracts of patients admitted in PGH's surgery department that contains data exclusively on trauma patients in PGH. Data from the same name but different identifier code were treated as a separate case if the time between consult is more than three months. Also, data with the same identifier code but a different name was considered a separate case if the history and diagnosis seem independent and a new pseudo-identifier code was assigned. Expert opinion was also taken into account during periodic meetings for the project.

The resulting database was a 10-year repository of road crash incidents from 2008 to 2017. Demographic variables (age, sex, city, admission date, consult type, and patient classification,), history of the patient (mechanism of injury [MOI], place of injury [POI], date of injury [DOI], and time of injury [TOI], and body parts injured) and clinical variables (patient outcomes, Glasgow coma score) were analyzed through descriptive statistics and reported using graphs and tables. The data was then migrated from Microsoft Excel to SPSS where inferential analysis such as Poisson regression on the number of body parts injured, and multinomial regression on patient outcomes was done.

\section{RESULTS}

From 2008 to 2017, 926/4922 (18.81\%) of road crash victims brought to $\mathrm{PGH}$ were women, compared to men (3993, 81.13\%). The trend was increasing, with the years from 2015 to 2017 accounting for half (55.62\%) of the total cases. The mean age of women patients was in the early $30 \mathrm{~s}$ $(31.28 \pm 19.97$ years). In addition, there were also more single (60.04\%) than married women patients (34.88\%) (Table 1).

Most of the women patients brought to PGH came from the Southern Tagalog Mainland (Region IV-A) (11.23\%) and National Capital Region (8.21\%). Most cases came from the provinces of Cavite (8.42\%), Metro Manila (8.10\%), and Laguna (2.05\%) (Table 1). The administrative regions mentioned are geographically close to $\mathrm{PGH}$, as $\mathrm{PGH}$ is a referral hospital for cases that cannot be handled by local primary healthcare providers.

Across the 10-year period, the year 2017 reported the highest number of road crash admissions at 201 cases (21.71\%). There is also an increasing trend of road crash admission across the years, with a sudden increase noticeable in the year 2015 (13.28\%) (Figure 1). 
The months with the highest recorded road crash admissions were June and July (5.61\%) and November and December (4.97\%). An increasing trend in road crashes was observed from January to July followed by a slight decrease before the number of cases increase again up until the month of December (Figure 2).

Table 1. Frequency distribution of women patients admitted due to road crash in PGH from 2008-2017 according to socio-demographic characteristics and geographical location $(n=926)$

\begin{tabular}{|c|c|c|}
\hline & Frequency & Percentage (\%) \\
\hline \multicolumn{3}{|l|}{ Sex } \\
\hline Male & 3993 & 81.13 \\
\hline Female & 926 & 18.81 \\
\hline Unknown & 3 & 0.06 \\
\hline Total & 4922 & 100.00 \\
\hline \multicolumn{3}{|l|}{ Civil Status } \\
\hline Single & 556 & 60.04 \\
\hline Married & 323 & 34.88 \\
\hline Unknown & 47 & 5.08 \\
\hline Total & 926 & 100.00 \\
\hline \multicolumn{3}{|l|}{ Region* } \\
\hline National Capital Region & 76 & 8.21 \\
\hline Central Luzon & 16 & 1.73 \\
\hline Southern Tagalog Mainland (4A) & 104 & 11.23 \\
\hline Southwestern Tagalog Region (4B) & 2 & 0.22 \\
\hline Bicol Region (5) & 2 & 0.22 \\
\hline Central Visayas (7) & 1 & 0.11 \\
\hline Unknown & 725 & 78.29 \\
\hline Total & 926 & 100.00 \\
\hline \multicolumn{3}{|l|}{ Province* } \\
\hline Metro Manila & 75 & 8.10 \\
\hline Cavite & 78 & 8.42 \\
\hline Bulacan & 9 & 0.97 \\
\hline Batangas & 4 & 0.43 \\
\hline Rizal & 2 & 0.22 \\
\hline Quezon & 3 & 0.32 \\
\hline Laguna & 19 & 2.05 \\
\hline Romblon & 1 & 0.11 \\
\hline Tarlac & 2 & 0.22 \\
\hline Pampanga & 3 & 0.32 \\
\hline Nueva Ecija & 2 & 0.22 \\
\hline Nueva Vizcaya & 1 & 0.11 \\
\hline Camarines Sur & 1 & 0.11 \\
\hline Masbate & 1 & 0.11 \\
\hline Unknown & 725 & 78.29 \\
\hline Total & 926 & 100.00 \\
\hline
\end{tabular}

*Region - the Philippines is composed of 16 regions; the regions in the Philippines are composed of provinces
Women patients admitted due to road crash had a median length of five hospital days. More road crash incidents occurred in the latter half (14.04\%) than the first half of the day $(8.86 \%)$. The time periods with the highest percentage of road crash incidents were the following: 01:00 to $3: 59(3.24 \%), 20: 00$ to $22: 59$ (4.43\%), and $15: 00$ to $18: 59$ (5.94\%) (Figure 3).

Among women road crash admissions, collision involving pedestrians was the most common (13.50\%), followed by the collisions involving vehicles (13.17\%) and damage to property $(5.51 \%)$. The types of vehicles most commonly involved in the crashes among was the motorcycle (9.72\%) and motor tricycle (2.38\%). Pedestrians accounted for the most common type (12.20\%), followed by drivers (6.16\%) and passengers (5.18\%). The incidence of risk factors associated with road crash incidents in women patients was low, with alcohol use being the most common (1.30\%). The use of seatbelt $(0.12 \%)$ and helmet (3.33\%) was low. Ambulance use was the least common mode of transport from site of crash to the hospital (0.33\%).

The median number of body parts injured was one body part. There were 307 cases (33.2\%) who experienced injury in one body part, while multiple injuries (83.65\%) accounted for majority of the cases. The injuries to the external area (43.72\%) and extremities (33.15\%). Injuries above the shoulder, represented by the head and neck, as well as the face accounted for $23.47 \%$ and $21.58 \%$ of in body parts injured, respectively. Most patients had at least 1 body part injured or more, which accounts for $79.06 \%$ of cases (Table 2).

The most common Glasgow coma score (GCS) category was "no brain injury" (GCS score $=15$ ) in $10.69 \%$ of cases. Overall, $3.67 \%$ of cases were considered to have a form of brain injury in reference to the GCS measure (Figure 4). Majority of cases had normal vital signs with only a few with abnormal blood pressure (7.34\%), heart rate (4.86\%), and respiratory rate $(7.34 \%)$.

Majority of women patients involved in road crash either recovered (19.44\%) or improved and (67.39\%). It is notable to mention that a recovered or improved patient

Table 2. Frequency distribution of women patients admitted due to road crash in PGH from 2008-2017 according to body parts injured, number of injury and consult type $(n=899)$

\begin{tabular}{lcc} 
Body Part Injured & Frequency & Percentage (\%) \\
Head and neck & 211 & 23.47 \\
Face & 194 & 21.58 \\
Chest & 135 & 15.02 \\
Abdomen & 84 & 9.34 \\
Extremity & 298 & 33.15 \\
External & 393 & 43.72 \\
Multiple injuries & 752 & 83.65 \\
No injury & 1 & 0.11 \\
\hline
\end{tabular}




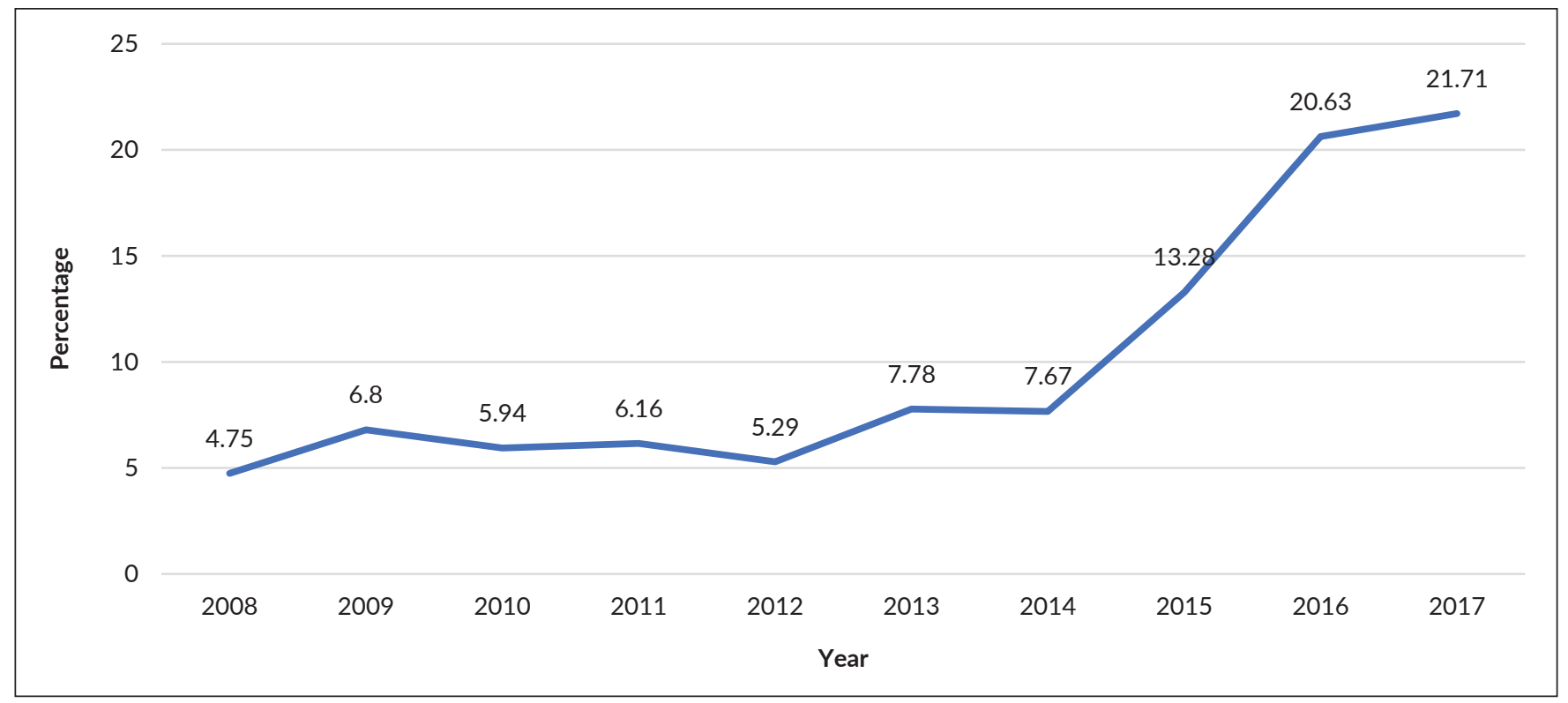

Figure 1. Percentage distribution of women patients admitted in PGH from 2008-2017 according to year of admission ( $\mathrm{n}=926)$.

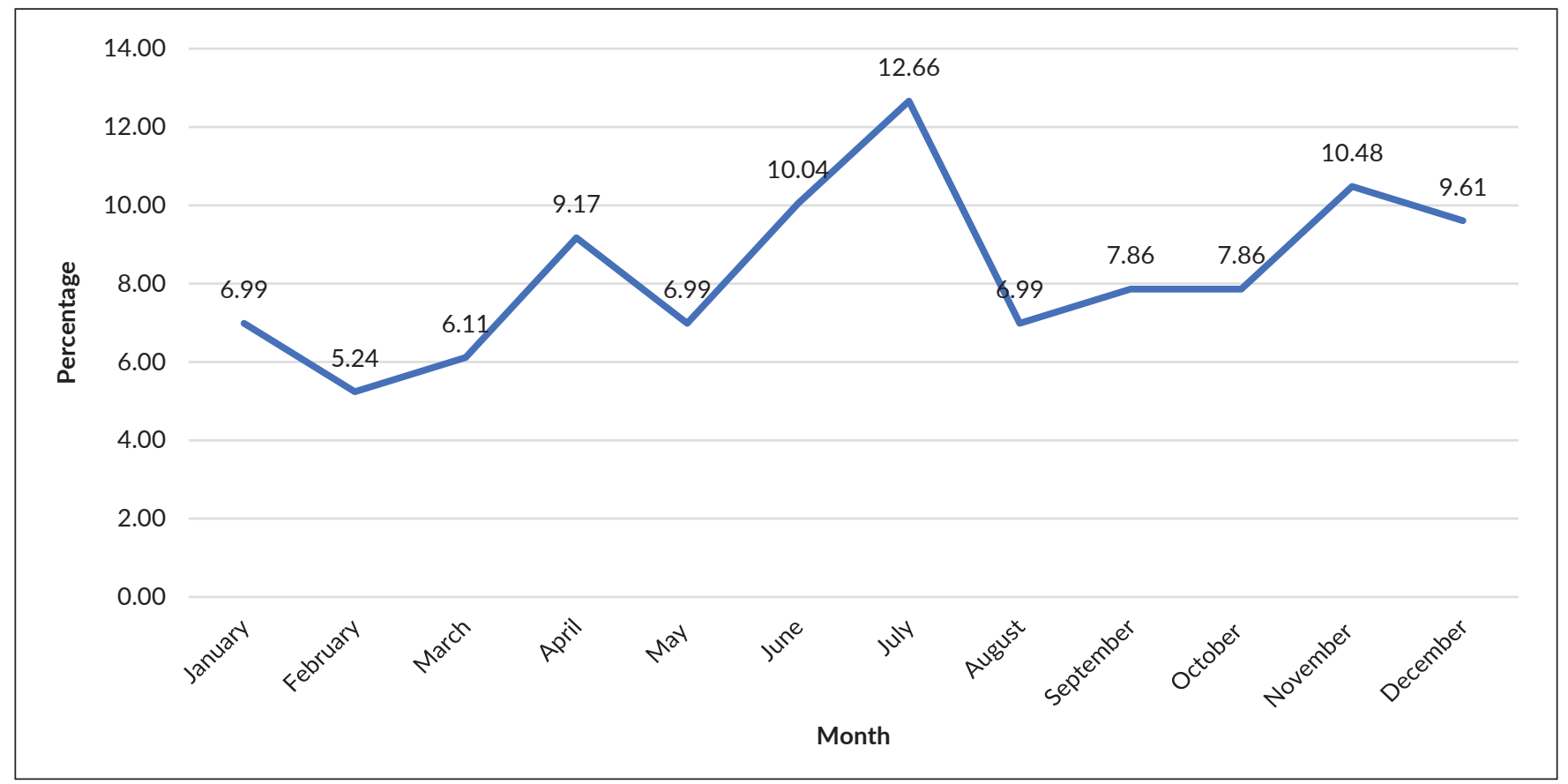

Figure 2. Percentage distribution of women patients admitted due to road crash in PGH from 2008-2017 according to month of admission $(n=229)$.

does not indicate the complete lack of comorbidities postrecovery. Among the cases, $2.70 \%$ died while $7.13 \%$ remained unchanged (Table 3).

The median length of hospital stay was shortest for head and neck injuries (Median: 5 days, Range: 466 days) and external injuries (Median: 5 days, Range: 466 days). Injuries to the extremity had the highest mean length of stay (Median: 10 days, Range: 466 days) (Table 4).
Head and neck injuries, external injuries, and respiratory rate had a negative association with length of hospital stay as these patients may have expired earlier. This would mean that an abnormal respiratory rate, head and neck injury, and external injury would lead to shorter hospital stays. Face injuries, extremity injuries, and an abnormal heart rate had a positive association with length of hospital stay. Specifically, patients who suffered injury in the extremity 


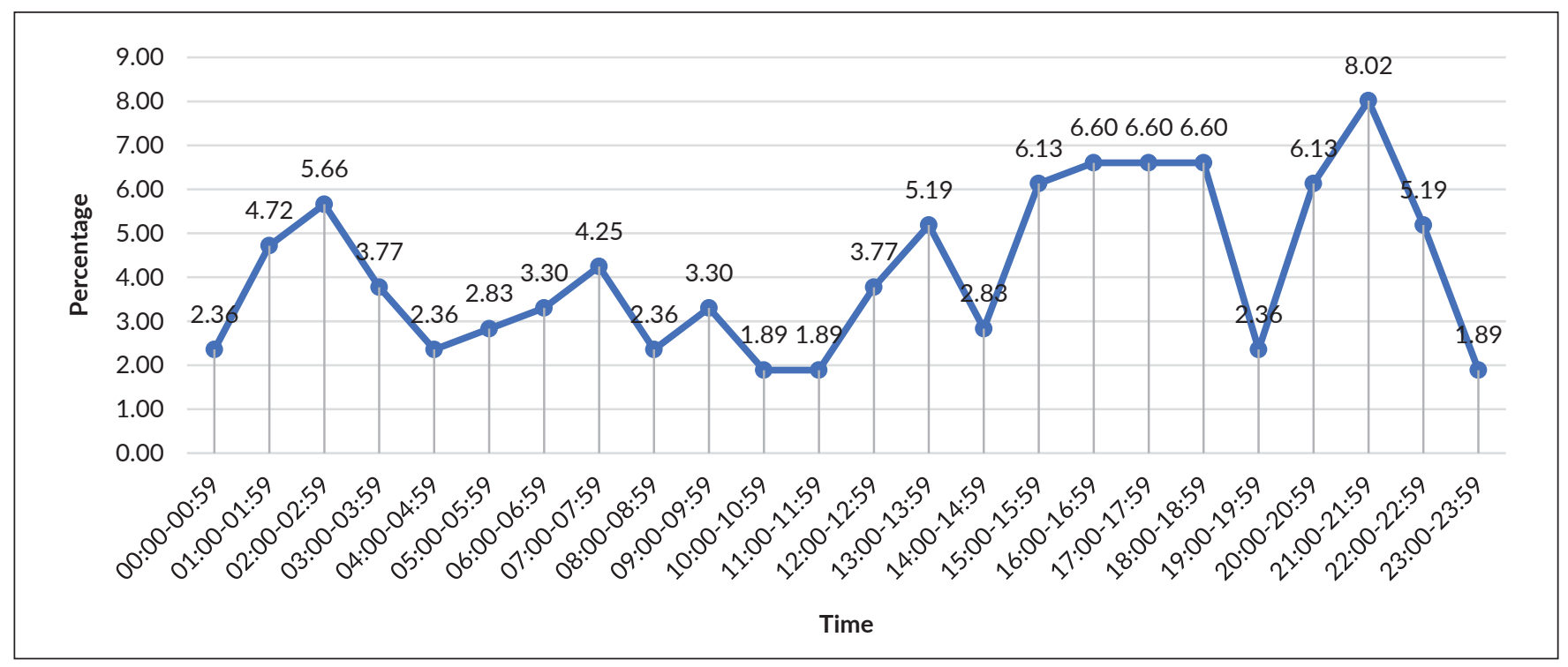

Figure 3. Percentage distribution of women patients admitted due to road crash in PGH from 2008-2017 according to time of injury $(n=212)$.

Table 3. Frequency distribution of women road crash admissions in PGH from 2008-2017 according to outcome $(n=926)$

\begin{tabular}{lcc}
\multicolumn{1}{c}{ Outcome } & Frequency & Percentage (\%) \\
\hline Recovered & 180 & 19.44 \\
Improved & 624 & 67.39 \\
Died & 25 & 2.70 \\
Unchanged & 66 & 7.13 \\
Unknown & 31 & 3.35 \\
Total & 926 & 100.00 \\
\hline
\end{tabular}

Table 4. Median length of hospital stay according to body parts injured among women road crash admissions in PGH from 2008-2017

\begin{tabular}{lcr} 
Body Part Injured & $\begin{array}{c}\text { Median Length of } \\
\text { Hospitalization (Days) }\end{array}$ & Range \\
\hline Head and neck & 5 & 466 \\
Face & 7 & 466 \\
Chest & 7 & 466 \\
Abdomen & 7 & 72 \\
Extremity & 10 & 466 \\
External & 5 & 466 \\
Multiple injuries & 5 & 467 \\
\hline
\end{tabular}

have an increased incidence for longer length of stay by 2.1 times than those who did not suffer injury in the extremity, holding all other variables constant. It should be noted that face injury was not significantly associated with length of hospital stay (Table 5).

For analysis of patient outcomes against GCS scores, significantly larger than expected death counts as well as

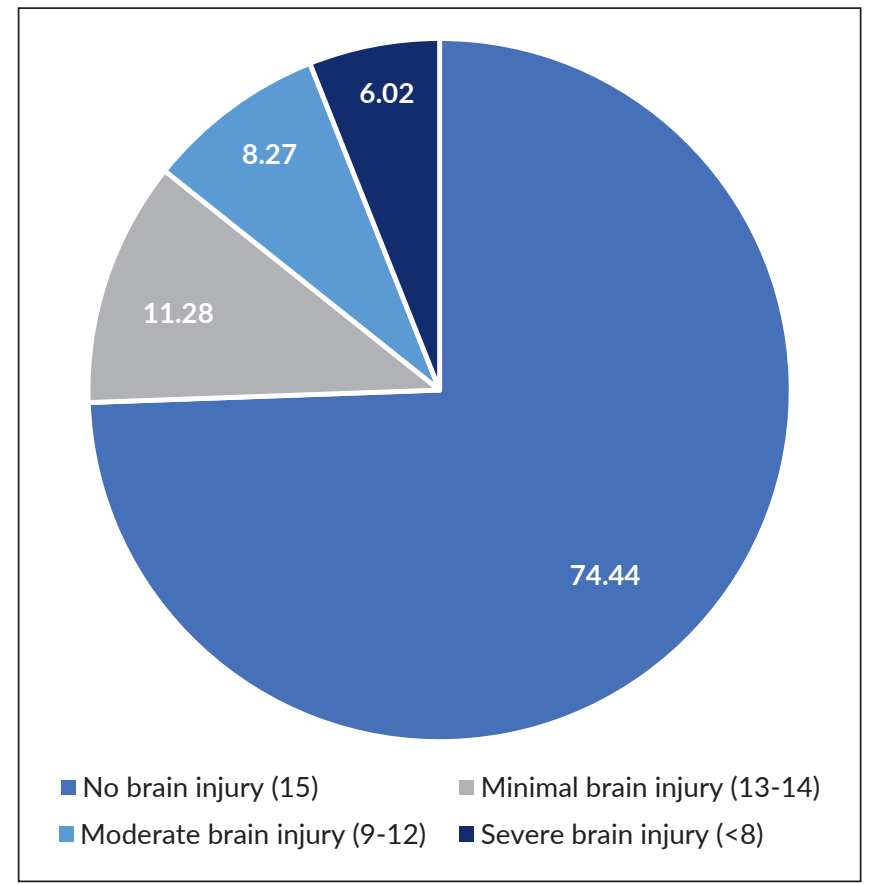

Figure 4. Percentage distribution of women patients admitted due to road crash in PGH from 2008-2017 according to Glasgow coma score $(n=133)$.

unchanged outcomes were observed for those who suffered severe brain injury $(p<0.0001)$. This implies that those with severe brain injury are at higher risk of mortality. The number of recoveries for those with no brain injury are also significantly larger than expected. This implies that those with no brain injure are at a lesser risk of mortality. Multinomial regression was also done with recovered cases 
Table 5. Body parts injured and vital signs versus length of hospital stay ( $N=184)$

\begin{tabular}{lcccc}
\multicolumn{1}{c}{ Parameters } & Incidence Rate Ratio & Standard Error & Confidence Interval & p-value \\
Head and Neck Injury & 0.843 & 0.0575 & $(0.753,0.944)$ & $0.003^{*}$ \\
Face Injury & 1.079 & 0.0433 & $(0.991,1.174)$ & 0.079 \\
Extremity Injury & 2.101 & 0.0412 & $(1.938,2.277)$ & $0.000^{*}$ \\
External Injury & 0.731 & 0.0390 & $(0.677,0.789)$ & $0.000^{*}$ \\
Abnormal Heart Rate & 1.323 & 0.0520 & $(1.195,1.465)$ & $0.000^{*}$ \\
Abnormal Respiratory Rate & 0.611 & 0.0484 & $(0.555,0.671)$ & $0.000^{*}$ \\
\hline
\end{tabular}

* Statistically significant

Table 6. Association of patient outcomes to body parts injured $(N=893)$

\begin{tabular}{lcccc}
\multicolumn{1}{c}{ Body Parts Injured } & Odds Ratio & Standard Error & Confidence Interval & p-value \\
Died & & & & \\
Head and neck & 4.938411 & 0.422445 & $(2.158,11.302)$ & 0.000157 \\
Abdomen & 3.337158 & 0.507323 & $(1.235,9.02)$ & 0.017528 \\
External & 0.247785 & 0.555421 & $(0.083,0.736)$ & 0.012006 \\
\hline Unchanged & & & & 0.054525 \\
Head and neck & 1.703340 & 0.277010 & $(0.99,2.932)$ & 0.058405 \\
Abdomen & 0.145982 & 1.016711 & $(0.02,1.071)$ & 0.006994 \\
External & 0.467144 & 0.282197 & $(0.269,0.812)$ & \\
\hline
\end{tabular}

used as reference. It was observed that suffering from a head and neck injury increased the odds ratio of dying by 4.94 times (CI: 2.158, 11.302, $p<0.01$ ). Suffering from an abdominal injury increased the odds ratio of dying by 3.33 times (CI:1.235- 9.02, $p<0.05)$. On the other hand, the presence of external injuries decreased the odds ratio of dying by a factor of 0.248 times (CI: $0.083-0.736, p<0.05$ ), as well as the odds ratio of unchanged status by $0.467(p<0.01)$ (Table 6).

\section{DISCUSSION}

In this study, women road crash admissions accounted for $18.81 \%$ compared to men $(81.13 \%)$. This is similar to studies by Giummarra et al. (2021) in Australia and Värnild et al. (2019) in Sweden, ${ }^{8}$ where most of their reported road crash victims were men. Among the women road crash admissions, $60.04 \%$ were single. A possible factor for these observations is the greater number of men than women in the working population. According to the Philippine Statistics Authority, as of January 2018, 7 out of 10 women were unemployed, further emphasizing the drastic difference between the number of women in the work force. Moreover, housewives were identified as among the women not part of the labor force. ${ }^{9}$ Although there was no specific correlation in this study, it is known that, culturally, married women tend to leave work to focus more on their families. This may account to a greater number of single women leaving home for work, while married women may opt to remain home to care for the family. ${ }^{10}$ The mean age of women admitted due to road crash injuries in this study was early 30s (31.28 \pm 19.97 years), which represents the productive age in the Philippines. Majority of employed individuals also fall within the ages 25 to 44 . $^{9}$

This study also observed a generally increasing trend among road crash cases every year for 10 years. A sudden increase was also observed in the year 2015 to 2017. According to the annual average daily traffic report around Metro Manila major roads of the Metro Manila Development Authority (MMDA) for the years 2014 and 2015, the average number of vehicles recorded was around 2.5 million daily, ranging from cars, public utility vehicles (PUJ), public utility buses (PUB), trucks, trailers, motorcycles, and tricycles. ${ }^{11,12}$ In the years 2016 and 2017, the average jumped to around 2.6 million and 2.7 million, respectively. ${ }^{13,14}$ These reports indicate that there has been a growing number of vehicles on the road throughout the years, which may reflect in an increase of road crash admissions observed in this study; however, the reports fail to account for roads outside Metro Manila. According to the WHO (2018), ${ }^{1}$ road crash continues to increase worldwide, which is observed in other studies as well. ${ }^{8,15}$

In this study, it was observed that the months with the highest cases were June and July (5.61\%), as well as November and December (4.97\%). These mostly corresponded with the results from the Metro Manila Accident Recording and Analysis System (MMARAS) Annual Report (2018) from MMDA, which reported the highest incidence of road crashes during the months of July to October, December, and March. However, contrary to what was observed in this study, MMARAS reported a decrease in the number of cases for the year 2018 in the month of November. ${ }^{16}$ It should be 
noted that these results only represent 1 year as compared to the study data which spans 10 years, and also does not differentiate between sexes. The high cases observed from June to July in this study may correspond to the rainy season of the country. A study by Giummarra et al. $(2021)^{7}$ found that crashes with no one at fault often involved poor or wet weather. Rainy or poorer weather may increase the chances of road crashes due to slippery roads and lower visibility. ${ }^{7}$ However, another study on traffic crashes in China found lower correlation of road crashes with rainy weather, which they attributed to a possible tendency of drivers to be more careful during bad weathers. ${ }^{17}$

According to this study, the median length of hospital stay for women is 5 days. The length of hospital stay usually corresponds to the severity of injuries sustained, but a study by Cullen et al. $(2021)^{18}$ observed no difference in the severity of injuries sustained between men and women. This is despite the frequent observation of higher risky behavior, lower risk perception and longer driving hours among men road users. ${ }^{18,19}$ However, another study among road crash victims in Saudi Arabia by Kashkooe et al. (2020) observed that males were more likely to experience longer hospital stays than females. ${ }^{20}$

The CALABARZON and National Capital Region, where Cavite and Metro Manila are located, respectively, registered the highest number of women admitted to PGH due to road crash. The hospital is also one of major government hospitals that cater to a high number of charity cases, which is also reflected in this study. Cavite and other cities that have high proportions of women admitted for road crash are near Manila, which makes the hospital one of the options for emergency road crash cases. This study reported $90.28 \%$ of women admitted for road crash as emergency cases. It is not uncommon for public hospitals to cater to patients from farther provinces as the Philippines has yet to evenly distribute the needed health infrastructure across the country. According to a review by the $\mathrm{WHO}$ on the state of the country's health system, NCR in Luzon has the most hospital beds (29\%), while only $20 \%$ are found outside Luzon. Moreover, private hospitals account for more than $50 \%$ of the hospitals in the country, leaving lesser options for patients to seek lower-cost treatment. ${ }^{21}$ The hospital in this study is one of the few and longest-standing trauma centers in the country, which may account for the few transfer patients (5.40\%) among women road crash admissions. The most common primary services for women road crash admissions were also those from the trauma service $(62.20 \%)$ and the surgeon on duty (18.14\%). An early study by Consunji et al. (2011), ${ }^{3}$ found that vehicular crashes were also among the most common trauma cases in the same hospital from the years 2004 to 2007; and, a significant number of these involved motorcycles. ${ }^{22}$ The WHO also reported that the Philippines still has poor emergency and pre-hospital services (WHO, 2018),${ }^{1}$ which may explain the low usage of ambulances $(0.33 \%)$ in this study.
According to the 2018 MMARAS data from MMDA, the occurrence of road crashes increased during the time periods of $01: 00$ to $02: 00$ and $14: 00$ to $20: 00,{ }^{16}$ which corresponds to the time periods observed to have increased road crashes in this study. The present study also exhibited a higher proportion of road crashes in the latter half of the day (14.04\%) than those that occurred in the early half (8.86\%). This may be due to the rush-hour that often occurs as individuals rush back home as work ends at around 5 or 6 in the evening. This was similar to the results of the study by Li et al. (2020) ${ }^{23}$ where they observed a higher association of road crashes during the latter half of the day among young and middle-aged drivers. Younger drivers, in particular, were also more likely to be involved in a car crash during the first few hours' past midnight. ${ }^{23}$ Crashes occurring at the latter hours of the night may also be likely to involve the use of alcohol or other intoxicating substances, which can affect a driver's judgement and predispose them to road crashes. ${ }^{24}$ It is important to note this as the study also observed that some women road crash admissions involved alcohol. Although the proportion was very small (1.30\%), the WHO has identified drunk driving as a road user behavior that increases the risk of road crash. ${ }^{1}$ This study also observed 2 $(0.22 \%)$ cases of fatigue out of the 926 women road crash admissions, which was found to increase the risk of road crash occurrence. ${ }^{25,26}$ Driver fatigue can be aggravated during night hours when visibility and the amount of light are low.

Among women road crash admissions, collisions involving pedestrians and vehicles had similar proportions, followed by damage to property as the mechanism of injury. The most common vehicle type involved in road crashes among women were motorcycles $(9.72 \%)$ and motor tricycles (2.38\%). In the Philippines, the most common modes of private transportation are the motorcycle and pedicabs. ${ }^{27}$ The high use of motorcycle and similar modes of transportation, such as the motor tricycle, in the country may be due to its lower cost compared to larger vehicles such as cars and vans. This trend is not only observed in the Philippines but in other middle-income countries as well, such as Iran, ${ }^{28}$ Vietnam, and Cambodia. ${ }^{29}$ Despite the frequent involvement of motorcycles among women road crash admissions, the reported helmet use was very low at only 3.33\%. However, this number could be higher than reported due to the missing data in the sample. Low helmet use is also a common problem in countries suffering from road crash incidents involving motorcycles. ${ }^{1,29}$

Cars, jeepney, and van involvement among the women road crash admissions also accounted for 2.59\%; while seatbelt use was only reported in $0.12 \%(n=805)$. Increasing the use of seatbelts is another form of preventing road crash injuries and was found to significantly reduce the chances of death among all car occupants. ${ }^{1}$ A study by Kwak et al. (2015) concluded that seatbelt use significantly reduces the odds of fatality among all types of car occupants. ${ }^{30}$ Similar results were observed in the study by $\mathrm{Li}$ et al. (2020) among 
rear-seat passengers as fatality risk was lower among cases wearing seat belts and other forms of restraints. ${ }^{31}$ Moreover, they observed that fatalities among males were more likely to be without any form of seat restraint compared to females. ${ }^{31}$ Although not observable in this study, seatbelt use among pregnant females may need to be revisited as some studies have shown seatbelt displacement caused by the growing fetus, and lesser seatbelt use due to increased discomfort. ${ }^{32,33}$ More research is needed regarding pregnant women and seatbelt use to determine its effects on maternal and child safety, as well as a comfortable and safe seatbelt design for the woman.

Women pedestrians yielded the highest proportion (12.20\%) of victim type involved in a road crash, followed by driver (6.16\%) and passenger (5.18\%). The high rates of pedestrian road crashes may be due to the pedestrian behavior, which a study by Debnath et al. $(2021)^{34}$ found was greatly influenced by the physical environment or available pedestrian-friendly infrastructure. Lower-income countries tend to have environments that promote unsafe behavior among pedestrians. Pedestrian pathways are usually plagued by various obstacles from parked vehicles to garbage obstructions, which forces the individual to veer away from the footpath to avoid these. ${ }^{34}$ Another study in Benin found that almost half of pedestrian road crashes occurred as they were walking on the road or leaving an intersection, while most fatalities occurred on poorly kept and damaged roads. ${ }^{35}$ Cities in the Philippines, such as Manila, also scored low in walkability with lacking infrastructure dedicated for pedestrians. This was further proved by the high rates of shared public transportation usage (i.e., jeepneys, tricycles) to travel only short distances. As there are less designated and safe areas for pedestrians to use, there will be more fatalities from this vulnerable road user. ${ }^{36}$ Driver behavior also has an effect on pedestrian safety as multiple studies have reported drivers colliding with pedestrians due to poorer experience and risky behaviors on the road. . $19,23,37$ These studies show that pedestrians remain as one of the most vulnerable, yet most neglected road user in terms of road infrastructure design that should promote their safety.

The improvement of walkability and safer pedestrian infrastructure are needed to reduce women road crash admissions and increase road safety. Traditionally, women are more likely to depend on others for transportation, ${ }^{38}$ which implies that it is more likely for women to be pedestrians or passengers. Moreover, women tend to prefer the use of public transportation methods compared to men who prefer cars and other private modes of transportation. The presence of an income gap between men and women, with women earning less, also accounts for the higher use of public transportation modes among women. ${ }^{5}$ The high frequency of pedestrians and passengers among women road crash admissions was a significant finding as pedestrians and passengers are more exposed on the road and, therefore, more vulnerable to severe injuries upon occurrence of a road crash. This highlights the vulnerability women face on the road every time they travel.
Among the sample of women road crash admissions, most of them sustained multiple injuries (83.65\%) involving the following body regions: external area (43.72\%), extremities (33.15\%), head and neck (23.47\%), and face (21.58\%). They also sustained a mean number of body parts injured of $1.42( \pm 1.03)$ areas. This implies that, on average, a female road crash admission would have more than one area injured. This was also observed with more than half of the sample sustaining at least one body part injured. In a study by Ngunde et al. (2019), ${ }^{39}$ they observed that most lowerextremity injuries were sustained from collisions involving bikes, particularly motor bikes, or pedestrians. The lower extremity commonly affected were the legs, thighs, and knees as these may be the most exposed body parts during collision. However, this study observed differences between injuries sustained between men and women, such that women had more injuries involving the ankle and hip. Lacerations and bruises were also common forms of injury in this study. ${ }^{39}$ These are similar to the present study as most of the women road crash victims were pedestrians and the most common vehicle involved was the motorcycle. External injuries that represent lacerations and bruises in any area were also among the most commonly sustained injuries in the present study. In addition to external injuries, injuries in the areas of the head, neck, and face were also common among female road crash admissions. It is worthy to note that the study sample had numerous cases of motorcycle involvement, yet poor helmet use. A study by Pai et al. (2017) ${ }^{40}$ among bicyclists and motorcyclists observed that the latter were more likely to be hospitalized from sustaining injuries to the head, and that being a woman motorcyclist increased these risks as well. Most of these injuries would also require care from trauma specialists and surgeons which is reflected in the common departments involved in the primary and coservices of patients. A surprising finding from this study is the high number of cases requiring pediatric surgery as coservice (11.88\%). This could mean that a significant number of the pediatric female road crash admissions required more invasive and serious treatments. Similar injury patterns as those observed in the sample of this study were also observed in the study of Fan et al. (2019). ${ }^{41}$ Their study among children motorcycle passengers observed that the most common body regions injured were the extremities, head, and face. Children without helmets were more likely to receive injuries to the head, yet majority of the children's passengers were not equipped with helmets. ${ }^{41}$ Other causes of pediatric road crash occurrence could be unlicensed handling of a vehicle (i.e., car, motorcycle) or being a pedestrian as observed in the study of Al-Hajj et al. (2020). ${ }^{42}$ This same study among road crashes involving children in Lebanon found no significant difference between men and women. ${ }^{42}$

A patient's vital signs and Glasgow coma scores (GCS) are important indicators of severity of injury and prognosis. In this study among women road crash admissions, it was observed that majority (10.69\%) had GCS scores indicating 
no brain injury, while $3.67 \%$ had levels indicating a level of brain injury. Moreover, most of their vital signs were within normal ranges with few cases exceeding or going below the normal range for blood pressure, heart rate, and respiratory rate. In a study by Brockamp et al. (2017) they observed that road crash patients involved in collisions with cars or motorbikes yielded higher severity scores for injuries to the head, abdomen, and extremities. ${ }^{43}$ They also were more likely to present with poorer GCS levels. Road crash victims, especially pedestrians, are prone to severe injuries from head trauma. During collision with a vehicle of any kind, the individual will first come into direct impact with the ground which will be followed by succeeding collisions (i.e., rolling, falling) caused by the momentum of the first impact. The first impact with the ground is what usually causes severe injury, especially if this involves areas of the head. The study by Tian et al. (2020) observed this when they simulated a collision between a pedestrian model and a vehicle. ${ }^{44}$ They noted that after impact to the head area, there were signs showing positive increase in intracranial pressure, which may be significantly fatal if not treated immediately. Fractures may also ensue as the force of impact is first received by the initial area of contact but will soon travel to the surrounding bone and tissue. ${ }^{44}$ Moreover, another study by Pai et al. (2019) among pedestrians in Taiwan found that those who had sustained injuries to the head or neck had high rates of fatalities as well..$^{45}$ Interestingly, the study also reported almost equal proportion between men and women pedestrian road crash victims. ${ }^{45}$ This was also evident in the study's analysis. Multinomial regression showed that injuries to the head and neck increased the odds ratio of mortality by 4.94 times; while, chi-square analysis showed that severe brain injury was significantly associated with patient death.

The generally normal vital signs among women road crash admissions were also reflected in the outcome of patients, such that $86.83 \%$ consisted of patients who improved or recovered. However, this does not imply lesser burden of disease from road crashes nor zero change in quality of life after recovery. In a study by Gopinath et al. (2017), they found that those who suffered from mild or moderate injuries from road crash incidents were also suffering from the effects of their disability on their physical and mental health, as well as their quality of life. ${ }^{46}$ Another study by Guest et al. (2018) observed that major depressive disorder and posttraumatic stress disorder were significantly prevalent among those who had survived and recovered from a road crash. ${ }^{47}$ After recovering from a road crash injury, patients are not only left to deal with the effects of their injury, but also on returning to work and seeking compensation for their injuries. ${ }^{46,47}$ The socio-economic consequences of disabilities and injuries from road crashes may be even graver for women compared to men. According to the United Nations, women with disabilities are more likely to experience more socioeconomic discrimination, which further increases their risk to abuse and exploitation. ${ }^{6,48}$ This is further aggravated by the high costs of treatment and rehabilitation even after recovery from road crash injuries. In fact, the study by van der Vlegel et al. (2020) observed that women road crash survivors yielded the highest health care cost. ${ }^{49}$ The costs attributed to health care needs and compromised productivity also tended to increase when the victim was a motorcyclist, bicyclist, or senior pedestrian. ${ }^{49}$

The study found that there was a negative association between length of hospital stay with head and neck injuries (OR 0.843; p < 0.01), external injuries (OR 0.731; p < $0.001)$, and abnormal respiratory rate (OR $0.611 ; \mathrm{p}<0.001)$. On the other hand, there was a positive association with extremity injuries (OR 2.101; $\mathrm{p}<0.001$ ) and abnormal heart rate (OR 1.323; $p<0.001)$. A possible reason for the decreased length of stay among patients with head or neck injuries may be due to the higher chances of fatality and decreased consciousness when injured in this area. High fatalities among road crash patients with head injury was observed in the study of Kourouma et al. (2019) as head injuries were also accompanied with lower GCS levels. ${ }^{50}$ In contrast, another study by Burkadze et al. (2021) observed longer hospital stays the more severe the injury to the brain but, they also observed that fatal brain injuries occurred the most among road crash victims. ${ }^{51}$

It is interesting to note that a review conducted by Gupte et al. (2019) found that there were sex differences regarding traumatic brain injuries, such that women were more likely to have worse prognosis from traumatic brain injuries. ${ }^{52}$ Women were also more likely to report worse traumatic brain injury symptoms than men. Differences in human studies between sexes may be due to subjectivity of symptom reporting and hormonal difference, because animal studies showed opposite and mixed findings using molecular parameters. ${ }^{52}$

External injuries refer to the injuries that present as concussions, abrasions, lacerations or burns in any area of the body. In this study, it was observed that external injuries were associated with shorter hospital stay. These external injuries may imply a more serious injury or accompany a more serious injury in another body area. This is because simple abrasions or lacerations alone will not commonly warrant admission into a hospital. External injuries that may imply more severe prognosis are those associated with internal bleeding. These injuries are not caused by penetrating injuries but by blunt injuries and are often fatal to the patient. In the study by Ntundu et al. (2019), most of the observed blunt abdominal injuries were among road crash patients. ${ }^{53}$ Even though their study reported longer hospital stay as severity increased, their sample only included those with abdominal injuries. Their reported mean hospital length of stay was 6 days, which was much shorter than the recorded mean length of hospital stays in the present study (10.38 \pm 27.08 days). Moreover, they reported high mortality among patients with abdominal injury due to the severity of other accompanying injuries, bleeding, and infection. ${ }^{53}$ However, the associated shorter length of hospital stay among those with external 
injuries may also be due to the faster recovery of patients. This is because of a lower odds ratio of death among patients with external injuries. In the context of the study, these external injuries are most likely not accompanied by abdominal injuries as a higher odds ratio of death of 3.34 times among those with abdominal injuries. Moreover, abdominal injuries only accounted for $9.34 \%$ of women road crash admissions.

An abnormal respiratory rate was also associated with shorter hospital stay, while an abnormal heart rate was associated with longer hospital stay. Respiratory rate and heart rate are significant indicators of oxygenation and circulation. These vital signs become abnormal after a traumatic event because the body is attempting to restore homeostasis. In a study by Singh et al. (2018), they observed that fatalities prior to hospital admission commonly presented with vital signs below the normal ranges; while, those who had higher vital signs were more likely to survive up to admission..$^{54}$ However, patients with extreme respiratory rates, whether high or low, will most likely need extra support for oxygenation such as from ventilators. The use of ventilators ${ }^{54}$ and presence of hypoxia or low oxygenation ${ }^{55}$ was associated with increased risk of mortality. The higher risk of mortality among patients presenting with oxygenation problems could explain the shorter hospital stay. On the other hand, a study by Bhandarkar et al. (2017) observed higher mortality rates among patients presenting with decreased blood pressure and heart rate levels and much less mortality rates when these were increased..$^{56}$ This would mean that patients with higher heart rates or blood pressures were more likely to survive. Another study by Azad et al. (2020), noted that tachycardia was associated with the need for surgical intervention among trauma patients, which would imply longer hospital stays for these patients. ${ }^{57}$ In the present study, many of the women road crash admissions required the involvement of surgical services, with the most frequent being the surgeon-on-duty (18.14\%). Although the analysis did not specify whether increased or decreased heart rate, majority of the cases among abnormal heart rate cases recorded higher readings. This is a limitation of the analysis, but the aforementioned studies are consistent with observing situations that would require longer hospital stay among patients with tachycardia.

Extremity injuries refer to injuries that involve sprains, fractures, amputations, and pelvic injuries. If severely damaged, these injuries may require surgical treatment to apply fixations or remove limbs. According to the study by Kashkooe et al. (2020), among road crash trauma patients, they observed that those requiring surgical intervention and treatment for infections were more likely to experience longer hospital stays. ${ }^{20}$ This is also similar to the findings of the study which observed that patients suffering from injury to the extremities experienced a longest average hospital stay (16.04 \pm 31.28 days) compared to cases with other injuries. Other reasons for prolonged hospital stay not directly observed in this study is the processing of insurance coverage for patients. Most of the women road crash admissions were charity patients, which means that their treatment was covered by the Philippine national health insurance company, PhilHealth. Multiple studies have cited that processing of insurance coverage for a patient's treatment may prolong the length of hospital stay. ${ }^{58,59}$

\section{CONCLUSION}

This study showed that a significant number of road crash admissions were women. Most were involved in collisions with motorcycles, and were pedestrians. Although most of the female road crash patients were reported to have improved or recovered, this does not disregard the presence of morbidities that may predispose them to a lower quality of life and discrimination.

There is evidence to support the gendered quality of road crash injuries, however, data on this is still lacking. This study in particular, observed that pedestrians and passengers made up the majority of women road crash admissions, which was consistent with public transportation patterns. This emphasizes their vulnerability on the road as pedestrians and passengers tend to be the least protected on the road. The researchers recommend that further research into the disabilities of women road crash victims and its effects on their life post-crash be conducted to further supplement the knowledge of the burden of road crashes. Policies should also focus on increasing safety measures for motorcyclists and pedestrians, especially among women, such as increasing helmet use and improving pedestrian walkability. It is also recommended that hospitals ensure an adequate recording of history variables relating to road traffic injuries to completely capture the factors that contribute to mortality and morbidity among women road crash patients.

\section{Statement of Authorship}

Both authors participated in the collection and analysis of data and approved the final version submitted.

\section{Author Disclosure}

Both authors declared no conflicts of interest.

\section{Funding Source}

The study was derived from the dataset of a study funded by the Department of Health under its program on Advancing Evidence-Assisted Decisions with Health Policy and Systems Research (AHEAD-HPSR) through the Philippine Council for Health and Research Development, and in coordination with the National Institutes of Health, University of the Philippines Manila.

\section{REFERENCES}

1. World Health Organization. Global Status Report on Road Safety 2018 [Internet]. Geneva: World Health Organization; 2018 [cited 2021 Jun 16]. Available from: https://www.who.int/publications/i/ item/9789241565684. 
2. Bachani AM, Peden M, Gururaj G, Norton R, Hyderr AA. Road Traffic Injuries. In: Mock CN, Nugent R, Kobusingye O, Smith AR, editors. Injury Prevention and Environmental Health. 3rd edition. Washington (DC): The International Bank for Reconstruction and Development/The World Bank; 2017. p. 35-54.

3. Consunji RJ, Serrato Marinas JP, Aspuria Maddumba JR, Dela Paz DA Jr. A profile of deaths among trauma patients in a university hospital: the Philippine experience. J Inj Violence Res. 2011 Jul; 3(2):85-9.

4. Global Road Safety Partnership [Internet]. Geneva: GSRP; c2021 [cited 2021 Jun 16]. Available from: https:/www.grsproadsafety.org/ programmes/countries/philippines/.

5. Kawgan-Kagan I. Are women greener than men? A preference analysis of women and men from major German cities over sustainable urban mobility. Transp Res Interdiscip Perspect. 2020 Nov; 8:100236.

6. Dammeyer J, Chapman M. A national survey on violence and discrimination among people with disabilities. BMC Public Health. 2018 Mar 15; 18(1):355

7. Giummarra MJ, Beck B, Gabbe BJ. Classification of road traffic injury collision characteristics using text mining analysis: Implications for road injury prevention. PLoS One. 2021 Jan 27; 16(1):e0245636. PubMed PMID: 33503030.

8. Värnild A, Larm P, Tillgren P. Incidence of seriously injured road users in a Swedish region, 2003-2014, from the perspective of a national road safety policy. BMC Public Health. 2019 Nov 27; 19(1):1576.

9. Philippine Statistics Authority. Employment Situation in January 2018 [Internet]. Quezon City: Philippine Statistics Authority; c2021 [updated 2018 Jun 14; cited 2021 Jun 17]. Available from: https://psa. gov.ph/statistics/survey/labor-and-employment/labor-force-survey/ title/Employment\%20Situation\%20in\%20January\%202018\%20 \%28Final\%20Results\%29.

10. Lu Y, Wang JS, Han WJ. Women's Short-Term Employment Trajectories Following Birth: Patterns, Determinants, and Variations by Race/Ethnicity and Nativity. Demography. 2017 Feb; 54(1):93-118.

11. Metropolitan Manila Development Authority. Summary: Metro Manila Annual Average Daily Traffic 2014 [Internet]. 2014 [cited 2021 Jun 17]. Available from: https://mmda.gov.ph/2-uncategorised/3345freedom-of-information-foi.html.

12. Metropolitan Manila Development Authority. Summary: Metro Manila Annual Average Daily Traffic (AADT) 2015 [Internet]. 2015 [cited 2021 Jun 18]. Available from: https://mmda.gov.ph/images/ Home/FOI/Annual-Average-Daily-Traffic-AADT/AADT-2015.pdf.

13. Metropolitan Manila Development Authority. Metro Manila AADT 2016 [Internet]. 2016 [cited 2021 Jun 18]. Available from: https:// mmda.gov.ph/images/Home/FOI/Annual-Average-Daily-TrafficAADT/AADT-2016.pdf.

14. Metropolitan Manila Development Authority. Metro Manila Annual Average Daily Traffic (AADT) 2017b Summary [Internet]. 2017 [cited 2021 Jun 18]. Available from: https://mmda.gov.ph/images/Home/ FOI/Annual-Average-Daily-Traffic-AADT/METROPOLITANMANILA-AADT-2017-summary.pdf.

15. Jiang B, Liang S, Peng ZR, Cong H, Levy M, Cheng Q, et al. Transport and public health in China: the road to a healthy future. Lancet. 2017 Oct 14;390(10104):1781-91.

16. Metropolitan Manila Development Authority. MMARAS Annual Report 2018 [Internet]. 2018 [cited 2021 Jun 18]. Available from: https://mmda.gov.ph/images/Home/FOI/MMARAS/MMARASAnnual-Report-2018.pdf.

17. Li G, Liao Y, Guo Q, Shen C, Lai W. Traffic crash characteristics in Shenzhen, China from 2014 to 2016. Int J Environ Res Public Health. 2021 Jan 28; 18(3):1176.

18. Cullen P, Möller H, Woodward M, Senserrick T, Boufous S, Rogers $\mathrm{K}$, et al. Are there sex differences in crash and crash-related injury between men and women? A 13-year cohort study of young drivers in Australia. SSM Popul Health. 2021 May 12; 14:100816. PubMed PMID: 34041353.

19. Klaitman SS, Solomonov E, Yaloz A, Biswas S. The Incidence of Road Traffic Crashes Among Young People Aged 15-20 Years: Differences in Behavior, Lifestyle and Sociodemographic Indices in the Galilee and the Golan. Front Public Health. 2018 Jul 26; 6:202.
20. Kashkooe A, Yadollahi M, Pazhuheian F. What factors affect length of hospital stay among trauma patients? A single-center study, Southwestern Iran. Chin J Traumatol. 2020 Jun; 23(3):176-80.

21. Dayrit MM, Lagrada LP, Picazo OF, Pons MC, Villaverde MC. The Philippines Health Systems Review [Internet]. New Delhi: World Health Organization, Regional Office for South-East Asia; 2018 [cited 2021 Jun 19]. Available from: https://apps.who.int/iris/ bitstream/handle/10665/274579/9789290226734-eng.pdf.

22. Consunji RJ, Larona AJL, Jumangit III AC, Ameratunga SN. Motorcycle-related trauma in the Philippines resulting in hospital admission: the epidemiology of cases at the Philippine General Hospital. Acta Med Philipp. 2013; 47(3):11-4.

23. Li G, Lai W, $\mathrm{Qu} X$. Association between crash attributes and drivers' crash involvement: a study based on police-reported crash data. Int J Environ Res Public Health. 2020 Dec 3; 17(23):9020.

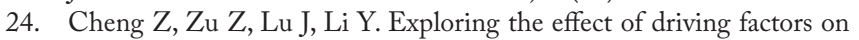
traffic crash risk among intoxicated drivers: a case study in Wujiang. Int J Environ Res Public Health. 2019 Jul 16; 16(14):2540.

25. Gottlieb DJ, Ellenbogen JM, Bianchi MT, Czeisler CA. Sleep deficiency and motor vehicle crash risk in the general population: a prospective cohort study. BMC Med. 2018 Mar 20; 16(1):44.

26. Shekari Soleimanloo S, White MJ, Garcia-Hansen V, Smith SS. The effects of sleep loss on young drivers' performance: A systematic review. PLoS One. 2017 Aug 31; 12(8):e0184002. PubMed PMID: 28859144.

27. Regidor JRF. Current State of Transportation Data and Statistics in the Philippines and Opportunities for Improvement Towards Usability [Internet]. Quezon City: Philippine Statistics Authority; 2019 [cited 2021 Jun 19]. Available from: https://psa.gov.ph/sites/ default/files/7.5.1\%20Current $\% 20$ State $\% 20$ of $\% 20$ Transportation $\% 20$ Data\%20and\%20Statistics\%20in\%20the\%20Philippines\%20and\%20 Opportunities\%20for\%20Improvement\%20Towards\%20Usability\%20 _0.pdf.

28. Sadeghi-Bazargani H, Samadirad B, Hosseinpour-Feizi H. Epidemiology of traffic fatalities among motorcycle users in East Azerbaijan, Iran. Biomed Res Int. 2018 Aug 19; 2018:6971904. PubMed PMID: 30211227.

29. Craft G, Van Bui T, Sidik M, Moore D, Ederer DJ, Parker EM, et al. A comprehensive approach to motorcycle-related head injury prevention: experiences from the field in Vietnam, Cambodia, and Uganda. Int J Environ Res Public Health. 2017 Nov 30; 14(12):1486.

30. Kwak BH, Ro YS, Shin SD, Song KJ, Kim YJ, Jang DB. Preventive effects of seat belt on clinical outcomes for road traffic injuries. J Korean Med Sci. 2015 Dec; 30(12):1881-8.

31. Li A, Shen S, Nwosu A, Ratnapradipa KL, Cooper J, Zhu M. Investigating traffic fatality trends and restraint use among rear-seat passengers in the United States, 2000-2016. J Safety Res. 2020 Jun; 73:9-16.

32. Hitosugi M, Koseki T, Kinugasa Y, Hariya T, Maeda G, Motozawa Y. Seatbelt paths of the pregnant women sitting in the rear seat of a motor vehicle. Chin J Traumatol. 2017 Dec; 20(6):343-6.

33. Hattori S, Hitosugi M, Moriguchi S, Baba M, Takaso M, Nakamura $\mathrm{M}$, et al. Factors influencing pregnant women's injuries and fetal loss due to motor vehicle collisions: a national crash data-based study. Healthcare (Basel). 2021 Mar 3; 9(3):273.

34. Debnath M, Hasanat-E-Rabbi S, Hamim OF, Hoque MS, McIlroy $\mathrm{RC}$, Plant KL, et al. An investigation of urban pedestrian behaviour in Bangladesh using the Perceptual Cycle Model. Saf Sci. 2021 Jun; 138:None. PubMed PMID: 34149186.

35. Glèlè-Ahanhanzo Y, Kpozèhouen A, Sossa-Jerôme C, Sopoh GE, Tedji $\mathrm{H}$, Yete $\mathrm{K}$, et al. "My right to walk, my right to live": pedestrian fatalities, roads and environmental features in Benin. BMC Public Health. 2021 Jan 19; 21(1):162.

36. Leather J. Walkability and pedestrian facilities in Asian cities state and issues [Internet]. Mandaluyong City: Asian Development Bank; 2011 [cited 2021 Jun 21]. Available from: https://www.adb.org/sites/ default/files/publication/28679/adb-wp17-walkability-pedestrianfacilities-asian-cities.pdf. 
37. Kemnitzer CR, Pope CN, Nwosu A, Zhao S, Wei L, Zhu M. An investigation of driver, pedestrian, and environmental characteristics and resulting pedestrian injury. Traffic Inj Prev. 2019;20(5):510-4.

38. Woodcock A, Mcdonagh D, Iqbal S, Faiz K, Harubain YABS. Gender transport poverty in low-middle income countries, and its effects on women's health and wellbeing. J Transp Health. 2019 Sep; 14:100716.

39. Ngunde PJ, Akongnwi ACN, Mefire CA, Puis F, Gounou E, Nkfusai $\mathrm{NC}$, et al. Prevalence and pattern of lower extremity injuries due to road traffic crashes in Fako Division, Cameroon. Pan Afr Med J. 2019 Jan 30; 32:53.

40. Pai CW, Chen YC, Lin HY, Chen PL. A population-based casecontrol study of hospitalisation due to head injuries among bicyclists and motorcyclists in Taiwan. BMJ Open. 2017 Nov 8; 7(11):e018574. PubMed PMID: 29122803.

41. Fan HP, Chiu WT, Lin MR. Effects of helmet nonuse and seating position on patterns and severity of injuries in child motorcycle passengers. BMC Public Health. 2019 Aug 8; 19(1):1070.

42. Al-Hajj S, Arjinian S, Hamadeh Z, Al-Zaghrini E, El Asmar K. Child transport injuries and deaths in Lebanon: a multicentre retrospective study. BMJ Open. 2020 Oct 26; 10(10):e037973. PubMed PMID: 33109652.

43. Brockamp T, Schmucker U, Lefering R, Mutschler M, Driessen A, Probst C, et al. Comparison of transportation related injury mechanisms and outcome of young road users and adult road users, a retrospective analysis on 24,373 patients derived from the TraumaRegister DGU ${ }^{\circledR}$. Scand J Trauma Resusc Emerg Med. 2017 Jun 14; 25(1):57.

44. Tian J, Zhang C, Wang Q. Analysis of craniocerebral injury in facial collision accidents. PLoS One. 2020 Oct 26;15(10):e0240359. PubMed PMID: 33104724.

45. Pai CW, Chen PL, Ma ST, Wu SH, Linkov V, Ma HP. Walking against or with traffic? Evaluating pedestrian fatalities and head injuries in Taiwan. BMC Public Health. 2019 Oct 10; 19(1):1280.

46. Gopinath B, Jagnoor J, Elbers N, Cameron ID. Overview of findings from a 2-year study of claimants who had sustained a mild or moderate injury in a road traffic crash: prospective study. BMC Res Notes. 2017 Feb 1; 10(1):76.

47. Guest R, Tran Y, Gopinath B, Cameron ID, Craig A. Prevalence and psychometric screening for the detection of major depressive disorder and post-traumatic stress disorder in adults injured in a motor vehicle crash who are engaged in compensation. BMC Psychol. 2018 Feb 21; 6(1):4.

48. United Nations [Internet]. New York: United Nations; c2021 [cited 2021 June 22]. Women and girls with disabilities; [about 5 screens]. Available from: https://www.un.org/development/desa/disabilities/ issues/women-and-girls-with-disabilities.html.
49. van der Vlegel M, Haagsma JA, de Munter L, de Jongh MAC, Polinder S. Health care and productivity costs of non-fatal traffic injuries: a comparison of road user types. Int J Environ Res Public Health. 2020 Mar 26; 17(7):2217.

50. Kourouma K, Delamou A, Lamah L, Camara BS, Kolie D, Sidibé S, et al. Frequency, characteristics and hospital outcomes of road traffic accidents and their victims in Guinea: a three-year retrospective study from 2015 to 2017. BMC Public Health. 2019 Jul 31; 19:1022.

51. Burkadze E, Axobadze K, Chkhaberidze N, Chikhladze N, Coman MA, Dulf D, et al. Epidemiology of traumatic brain injury in georgia: a prospective hospital-based study. Risk Manag Healthc Policy. 2021 Mar 12;1 4:1041-51.

52. Gupte R, Brooks W, Vukas R, Pierce J, Harris J. Sex differences in traumatic brain injury: what we know and what we should know. J Neurotrauma. 2019 Nov 15; 36(22):3063-91.

53. Ntundu SH, Herman AM, Kishe A, Babu H, Jahanpour OF, Msuya $\mathrm{D}$, et al. Patterns and outcomes of patients with abdominal trauma on operative management from northern Tanzania: a prospective single centre observational study. BMC Surg. 2019 Jun 26; 19(1):69.

54. Singh M, Pal R, Yarasani P, Bhandarkar P, Munivenkatappa A, Agrawal A. International Classification of Diseases-Based audit of the injury database to understand the injury distribution in patients who have sustained a head injury (International Classification of Diseases Codes: S00-S09). J Emerg Trauma Shock. 2018 Oct-Dec; 11(4):253-64.

55. Newberry JA, Bills CB, Matheson L, Zhang X, Gimkala A, Ramana Rao GV, et al. A profile of traumatic injury in the prehospital setting in India: A prospective observational study across seven states. Injury. 2020 Feb; 51(2):286-93.

56. Bhandarkar P, Munivenkatappa A, Roy N, Kumar V, Samudrala VD, Kamble J, et al. On-admission blood pressure and pulse rate in trauma patients and their correlation with mortality: Cushing's phenomenon revisited. Int J Crit Illn Inj Sci. 2017 Jan-Mar; 7(1):14-7.

57. Azad AD, Kong VY, Clarke DL, Laing GL, Bruce JL, Chao TE. Use of vital signs in predicting surgical intervention in a South African population: A cross-sectional study. Int J Surg. 2020 Jul; 79:300-4.

58. Holzmacher JL, Townsend K, Seavey C, Gannon S, Schroeder M, Gondek S, et al. Association of expanded Medicaid coverage with hospital length of stay after injury. JAMA Surg. 2017 Oct 1; 152(10):960-6.

59. Shin KW, Lee HJ, Nam CM, Moon KT, Park EC. Hospital characteristics related to the hospital length of stay among inpatients receiving invasive cervical discectomy due to road traffic accidents under automobile insurance in South Korea. BMC Health Serv Res. 2017 Aug 16; 17(1):567. 